\title{
Assessment of unilateral afferent pupillary defects by pupillography
}

\author{
P. N. FISON, D. J. GARLICK, AND S. E. SMITH \\ From the Department of Pharmacology and Eye Department, St. Thomas's Hospital and Medical School, \\ London
}

SUMMARY A pupillographic technique, an adaptation of the swinging light test, is described for the measurement of unilateral afferent pupillary defects. In normal persons it yielded accurate, reproducible estimates of the magnitude of artificial afferent defects made with neutral filters of 1 to $4 \log$ units density. In 15 studies on 8 patients with unilateral optic neuritis and 2 with unilateral compressive lesions the measured afferent pupillary defects correlated closely with both visual acuity and visual threshold deficits. Measurement of the pupillary defect underestimated severe degrees of impairment revealed by visual threshold determination. Discrepancies between pupillary defect and visual acuity were observed in the 2 patients with compressive lesions and in 1 patient who had a central scotoma 4 months after an attack of optic neuritis.

Clinical assessment of the severity of damage caused by an attack of optic neuritis may be based on the appearance of the optic disc or on the determination of visual acuity, colour vision, visual field defects, the macular light threshold, the occipital visual evoked response (VER), or the pupillary light reflex. Previous pupillographic studies have indicated that the light reflex is qualitatively normal in this condition and that its reduced amplitude can be matched by eliciting the light reflex in a normal eye with light of reduced intensity (Lowenstein, 1954a; Thompson, 1966).

In the present study of unilateral afferent defects this observation has been employed in an adaptation of the swinging flashlight test (Levatin, 1959). With this technique the requisite degree of attenuation of the stimulus light applied to the normal eye has been used as a quantitative measure of the defect in the affected eye. The reliability of the method is assessed by using artificial afferent defects in normal persons and a small study performed on patients with unilateral optic nerve lesions.

\section{Methods}

Subjects. Measurements were performed on 13 healthy volunteers aged 20 to 30 years and on 10 patients with clinically diagnosed unilateral afferent

Address for reprints: Dr S. E. Smith, Department of Pharmacology, St. Thomas's Hospital Medical School, London SE1 7EH defects. Outline clinical details of the patients are given in the 'results' section.

Visual acuity. The corrected visual acuity of both eyes in patients was recorded. For quantitative comparison with other measurements the values obtained were scaled for visual efficiency by the method of Snell and Sterling (1925). Visual acuity less than $6 / 60$ was scaled zero efficiency.

Pupillography. Pupil diameters were recorded continuously in the dark with a Whittaker Corporation Series 1800 binocular infrared TV pupillometer. Light reflexes were elicited with light from Sylvania 2-watt tungsten arc lamps. Each lamp output was focused on the model pupil and thus, as closely as possible, in the plane of the subject's pupil with a beam diameter of $2 \mathrm{~mm}$, that is, smaller than the pupil diameter (Maxwellian view). The mean angle of incidence was $7^{\circ} 31^{\prime}$ to the temporal side of the visual fixation point and in the same horizontal plane. Light intensities were varied with Kodak Wratten neutral density filters.

Visual threshold. Visual thresholds in both eyes of patients were obtained with the pupillometer light sources by a forced-choice method adapted from that described for the measurement of taste thresholds by Harris and Kalmus (1949). The patients were dark-adapted by wearing dark red goggles for 30 minutes. At each light intensity 3 sets of 3 auditory signals, 4 seconds apart, were given, 1 signal in each set being accompanied by a light stimulus of 0.5 second duration from the pupillometer as described above. Correct interpretation of 
when the light stimuli were given was taken to indicate that the subject could see the light, and the intensity was therefore above threshold. If the subject interpreted correctly, further sets of signals were given with successively lower intensities of light stimuli until the subject made errors. The visual threshold was recorded as the lowest intensity (in log density units of filtration) which could be correctly distinguished from no light at all. The chance of guessing correctly is $1 / 27(\mathrm{P}=0.037)$.

Pupillary afferent defect. Artificial unilateral afferent defects were created in healthy volunteers by placing neutral density filters ( 1 to $4 \log$ units) before one of the stimulus lights. The magnitude of this artificial defect in volunteers and of the real defect in patients was assessed by a modification of the swinging light test. The volunteers were tested on two occasions at least 1 week apart, defects of 1 and 2 $\log$ units being tested without, and defects of 3 and $4 \log$ units with, dark adaptation. Left and right
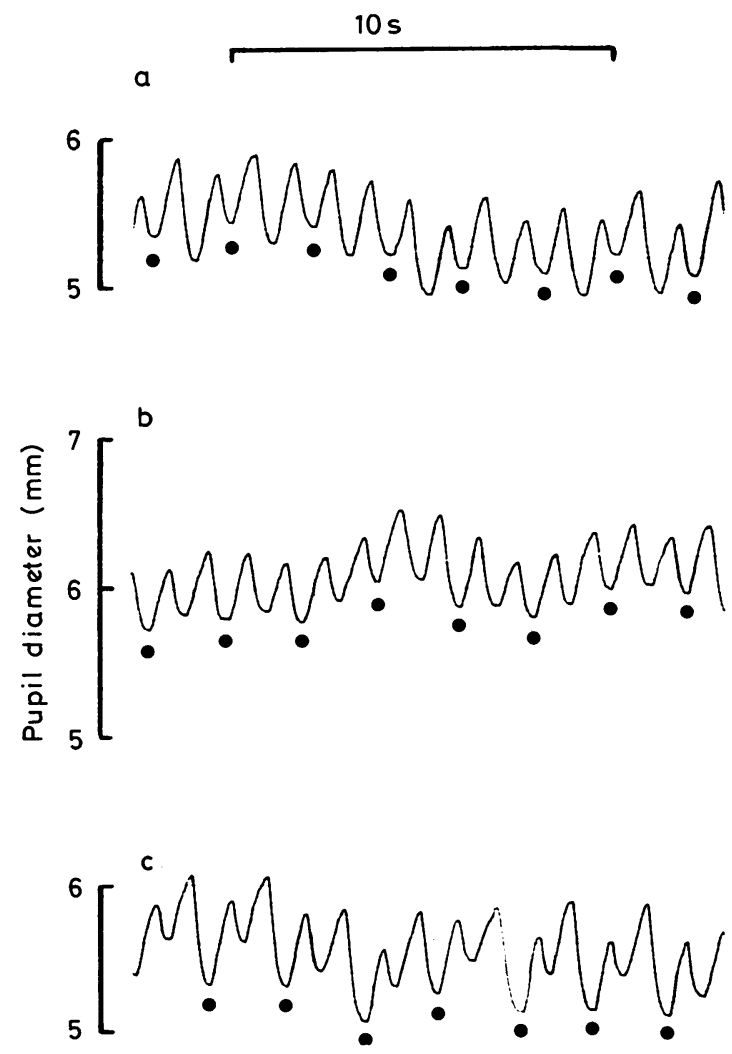

Fig. 1 Pupil response of normal subject with right-sided 1 log unit artificial afferent defect following alternating light stimulation $(\mathrm{O}=$ left eye) at different stimulus intensities. Filter added (L): (a) 1.4 ; (b) $1 \cdot 0$; (c) $0.4 \mathrm{log}$ units. Pupil responses are approximately balanced in (b)

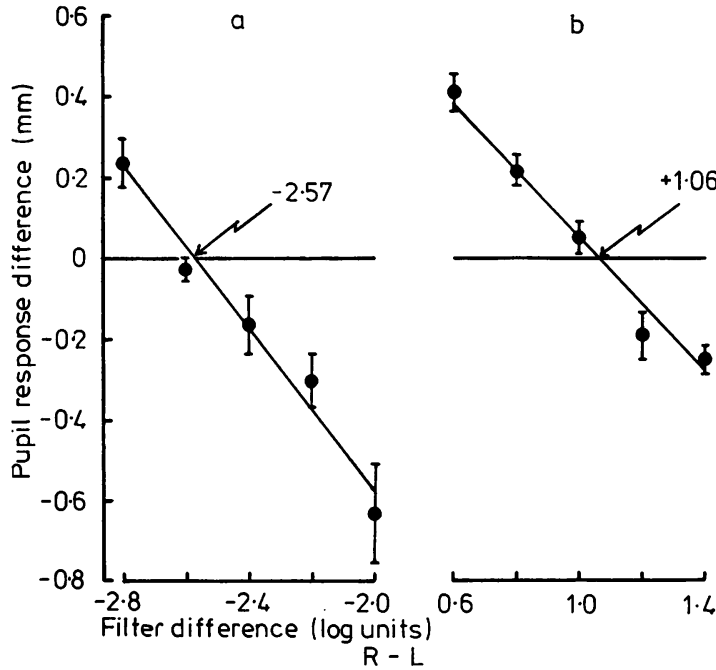

Fig. 2 Pupil contraction differences (mean $\pm S E M$ ) following alternating light stimulation at different relative stimulus intensities in: (a) Patient no. 1; and (b) normal subject no. 1 with 1 log unit artificial afferent defect

eyes were subjected to alternating light stimuli of 1 second duration without interruption and pupil responses to about 12 pairs of stimuli recorded. Responses were obtained from 1 pupil only, preliminary measurements being used to assess that this pupil was not subject to alternating contraction anisocoria (Lowenstein, 1954b). Neutral density filters were subsequently added to the light sources illuminating the unaffected eye so as to obtain approximately balanced responses to alternating stimulation. The test was repeated using 5 or more filter values, differing by $0.2 \log$ unit steps, around the approximate balance point. The mean difference in pupil response between the 2 sides, after exclusion of the first 4 responses, which were usually larger than the remainder, was plotted graphically against filter values and the balance point (in $\log$ units of filtration) obtained by linear regression, by the method of least squares (Snedecor and Cochran, 1967). Examples of pupil diameter traces at 3 filtration values and of 2 regression plots are given in Figs. 1 and 2 respectively.

\section{Results}

ARTIFICIAL AFFERENT DEFECTS IN VOLUNTEERS

The results of duplicate measurements of artificial afferent defects with $95 \%$ confidence limits and correlation coefficients are given in Table 1. The precision of the method was such that 16 of the 26 
Table 1 Duplicate measurements of artificial afferent defects in 13 normal persons

\begin{tabular}{|c|c|c|c|c|}
\hline \multirow{2}{*}{ No. } & \multirow{2}{*}{$\begin{array}{l}\text { Applied defect } \\
\text { (log units) }\end{array}$} & \multicolumn{3}{|c|}{ Pupil afferent defect (log units) } \\
\hline & & Mean & $95 \%$ confidence limits & $-r^{*}$ \\
\hline 1 & $1 \cdot 0$ & $\begin{array}{l}1 \cdot 06 \\
1 \cdot 14\end{array}$ & $\begin{array}{l}0 \cdot 75-1 \cdot 38 \\
0 \cdot 81-1 \cdot 48\end{array}$ & $\begin{array}{l}0.93 \\
0.92\end{array}$ \\
\hline 2 & $1 \cdot 0$ & $\begin{array}{l}1 \cdot 06 \\
1 \cdot 25\end{array}$ & $\begin{array}{l}0.56-1.57 \\
0.72-1 \cdot 79\end{array}$ & $\begin{array}{l}0 \cdot 85 \\
0 \cdot 84\end{array}$ \\
\hline 3 & $1 \cdot 0$ & $\begin{array}{l}0.90 \\
1 \cdot 16\end{array}$ & $\begin{array}{l}0.62-1 \cdot 17 \\
0.87-1 \cdot 45\end{array}$ & $\begin{array}{l}0.95 \\
0.94\end{array}$ \\
\hline 4 & $1 \cdot 0$ & $\begin{array}{l}0.89 \\
1.03\end{array}$ & $\begin{array}{r}-0.13-1.91 \\
0.52-1.57\end{array}$ & $\begin{array}{l}0 \cdot 87 \\
0 \cdot 84\end{array}$ \\
\hline 5 & $2 \cdot 0$ & $\begin{array}{l}2 \cdot 14 \\
1 \cdot 96\end{array}$ & $\begin{array}{l}1 \cdot 64-2 \cdot 64 \\
1 \cdot 31-2 \cdot 60\end{array}$ & $\begin{array}{l}0.85 \\
0.79\end{array}$ \\
\hline 6 & $2 \cdot 0$ & $\begin{array}{l}1 \cdot 85 \\
1 \cdot 57\end{array}$ & $\begin{array}{l}1 \cdot 36-2 \cdot 35 \\
0 \cdot 96-2 \cdot 15\end{array}$ & $\begin{array}{l}0.86 \\
0.81\end{array}$ \\
\hline 7 & $2 \cdot 0$ & $\begin{array}{l}2 \cdot 09 \\
2 \cdot 14\end{array}$ & $\begin{array}{l}1 \cdot 11-3.08 \\
1 \cdot 72-2 \cdot 57\end{array}$ & $\begin{array}{l}0 \cdot 84 \\
0 \cdot 89\end{array}$ \\
\hline 8 & $2 \cdot 0$ & $\begin{array}{l}1 \cdot 65 \\
2 \cdot 16\end{array}$ & $\begin{array}{l}0 \cdot 68-2 \cdot 58 \\
1 \cdot 56-2 \cdot 77\end{array}$ & $\begin{array}{l}0.67 \\
0.81\end{array}$ \\
\hline 9 & $3 \cdot 0$ & $\begin{array}{l}3 \cdot 11 \\
2 \cdot 79\end{array}$ & $\begin{array}{l}2 \cdot 61-3 \cdot 62 \\
2 \cdot 23-3 \cdot 33\end{array}$ & $\begin{array}{l}0.85 \\
0 \cdot 83\end{array}$ \\
\hline 10 & $3 \cdot 0$ & $\begin{array}{l}2 \cdot 79 \\
3 \cdot 08\end{array}$ & $\begin{array}{l}2 \cdot 04-3 \cdot 52 \\
0 \cdot 88-5 \cdot 35\end{array}$ & $\begin{array}{l}0 \cdot 75 \\
0 \cdot 40\end{array}$ \\
\hline 11 & $3 \cdot 0$ & $\begin{array}{l}3 \cdot 54 \\
3 \cdot 60\end{array}$ & $\begin{array}{l}2 \cdot 91-4 \cdot 20 \\
2 \cdot 86-4 \cdot 40\end{array}$ & $\begin{array}{l}0 \cdot 79 \\
0 \cdot 74\end{array}$ \\
\hline 12 & $4 \cdot 0$ & $\begin{array}{l}3.68 \\
3.68\end{array}$ & $\begin{array}{l}2 \cdot 08-5 \cdot 13 \\
2 \cdot 75-4 \cdot 57\end{array}$ & $\begin{array}{l}0.51 \\
0.68\end{array}$ \\
\hline 13 & $4 \cdot 0$ & $\begin{array}{l}4 \cdot 20 \\
4 \cdot 31\end{array}$ & $\begin{array}{l}3 \cdot 50-4 \cdot 92 \\
3 \cdot 48-5 \cdot 17\end{array}$ & $\begin{array}{l}0.76 \\
0.70\end{array}$ \\
\hline
\end{tabular}

determinations fell within $0 \cdot 2 \log$ units of the correct value and only 3 determinations differed by more than $0.4 \log$ units. The correlation coefficients indicated that the precision was slightly better at low than high afferent defect values. A paired $t$ test indicated that the measured defect did not differ significantly from the correct value $(t=0.64, \mathrm{P}>0.05)$, and the measurement showed satisfactory repeatability (intrapair correlation $r=0.98$ ).

\section{AFFERENT DEFECTS IN PATIENTS}

Visual acuity, visual threshold, and pupil afferent defect values obtained in 10 patients with clinically diagnosed unilateral defects are given in Table 2. Acuity and threshold differences and afferent defects are expressed as right minus left values; negative figures therefore indicate right-sided, and positive figures left-sided, defects. All but 2 patients ( 2 and 8 ) showed impaired threshold and or an afferent defect on testing.

Repeated measurements were performed on 3 patients (nos. 1, 9, and 10) within a few weeks of the onset of retrobulbar neuritis. In 2 of these (9 and 10) clinical improvement was accompanied by improvement in the visual threshold and reduction of the measured afferent defect.

Comparison of the magnitude of the intraocular differences in visual acuity (the scaled measure being used) and threshold and the afferent defect showed substantial agreement between individual values. High correlation coefficients between the 3 para-

Table 2 Visual acuity, threshold, and afferent pupillary defect of 10 patients with unilateral disease

\begin{tabular}{|c|c|c|c|c|c|c|c|c|c|c|c|c|c|c|}
\hline \multirow{2}{*}{$\begin{array}{l}\text { Case } \\
\text { no. }\end{array}$} & \multirow{2}{*}{$\operatorname{Sex}$} & \multirow{2}{*}{ Age } & \multirow{2}{*}{\multicolumn{2}{|c|}{ Diagnosis }} & \multirow{2}{*}{$\begin{array}{l}\text { Weeks } \\
\text { since } \\
\text { onset of } \\
\text { symptoms }\end{array}$} & \multicolumn{2}{|c|}{ Visual acuity } & \multicolumn{2}{|c|}{ Scaled } & \multirow[b]{2}{*}{ Diff. } & \multicolumn{3}{|c|}{$\begin{array}{l}\text { Visual threshold } \\
\text { (log units) }\end{array}$} & \multirow{2}{*}{$\begin{array}{l}\text { Afferent } \\
\text { pupillary } \\
\text { defect } \\
\text { (log units) }\end{array}$} \\
\hline & & & & & & $R$ & $L$ & $R$ & $L$ & & $R$ & $L$ & Diff. & \\
\hline 1 & $\mathbf{M}$ & 25 & $\mathbf{R}$ & $\begin{array}{l}\text { optic } \\
\text { neuritis }\end{array}$ & $\begin{array}{l}2 \\
6\end{array}$ & $\begin{array}{r}<6 / 60 \\
6 / 60\end{array}$ & $\begin{array}{l}6 / 5 \\
6 / 5\end{array}$ & $\begin{array}{r}0 \\
20\end{array}$ & $\begin{array}{l}103 \\
103\end{array}$ & $\begin{array}{r}-103 \\
-83\end{array}$ & $\begin{array}{l}4 \cdot 9 \\
4 \cdot 5\end{array}$ & $\begin{array}{l}8 \cdot 4 \\
8 \cdot 6\end{array}$ & $\begin{array}{l}-3 \cdot 5 \\
-4 \cdot 1\end{array}$ & $\begin{array}{l}-2 \cdot 57 \\
-2 \cdot 48\end{array}$ \\
\hline 2 & $\mathbf{M}$ & 29 & $\mathbf{R}$ & optic neuritis & 104 & $6 / 5$ & $6 / 6$ & 103 & 100 & +3 & $8 \cdot 7$ & $8 \cdot 6$ & $+\mathbf{0} \cdot \mathbf{1}$ & $+0 \cdot 32$ \\
\hline 3 & $\mathbf{F}$ & 46 & $\mathbf{R}$ & optic neuritis & 78 & $6 / 12$ & $6 / 5$ & 84 & 103 & -19 & $7 \cdot 9$ & $8 \cdot 4$ & -0.5 & $-0 \cdot 78$ \\
\hline 4 & $\mathbf{M}$ & 20 & $\mathrm{~L}$ & optic neuritis & 52 & $6 / 5$ & $<6 / 60$ & 103 & 0 & +103 & $9 \cdot 3$ & $5 \cdot 8$ & $+3 \cdot 5$ & $+2 \cdot 87$ \\
\hline 5 & $\mathbf{F}$ & 15 & $\mathbf{R}$ & $\begin{array}{l}\text { optic nerve } \\
\text { meningioma }\end{array}$ & 22 & $6 / 12$ & $6 / 5$ & 84 & 103 & -19 & $4 \cdot 8$ & $8 \cdot 8$ & $-4 \cdot 0$ & $-1 \cdot 36$ \\
\hline 6 & $\mathbf{M}$ & 31 & L & $\begin{array}{l}\text { optic } \\
\text { neuritis }\end{array}$ & $\begin{array}{l}26 \\
30\end{array}$ & $\begin{array}{l}6 / 5 \\
6 / 5\end{array}$ & $\begin{array}{l}6 / 36 \\
6 / 36\end{array}$ & $\begin{array}{l}103 \\
103\end{array}$ & $\begin{array}{l}41 \\
41\end{array}$ & $\begin{array}{r}+62 \\
+62\end{array}$ & $\begin{array}{l}8 \cdot 8 \\
8 \cdot 1\end{array}$ & $\begin{array}{l}4 \cdot 6 \\
7 \cdot 3\end{array}$ & $\begin{array}{r}+4 \cdot 2 \\
+0.8\end{array}$ & $\begin{array}{r}1 \cdot 52 \\
+1 \cdot 14\end{array}$ \\
\hline 7 & $\mathbf{M}$ & 18 & $\mathbf{R}$ & orbital compression & 8 & $6 / 5$ & $6 / 5$ & 103 & 103 & 0 & $8 \cdot 5$ & $8 \cdot 5$ & 0 & -1.08 \\
\hline 8 & $\mathbf{F}$ & 29 & L & $\begin{array}{l}\text { optic neuritis, } \\
\text { central scotoma }\end{array}$ & 16 & $6 / 6$ & $6 / 36$ & 100 & 41 & +59 & $8 \cdot 2$ & $8 \cdot 4$ & -0.2 & 0 \\
\hline 9 & $\mathbf{F}$ & 18 & $\mathbf{R}$ & $\begin{array}{l}\text { optic } \\
\text { neuritis }\end{array}$ & $\begin{array}{l}3 \\
5\end{array}$ & $\begin{array}{l}6 / 18 \\
6 / 6\end{array}$ & $\begin{array}{l}6 / 5 \\
6 / 5\end{array}$ & $\begin{array}{r}70 \\
100\end{array}$ & $\begin{array}{l}103 \\
103\end{array}$ & $\begin{array}{l}-33 \\
-\quad 3\end{array}$ & $\begin{array}{l}6 \cdot 4 \\
8 \cdot 2\end{array}$ & $\begin{array}{l}7 \cdot 5 \\
8 \cdot 3\end{array}$ & $\begin{array}{l}-1 \cdot 1 \\
-0 \cdot 1\end{array}$ & $\begin{array}{l}-0.74 \\
-0.03\end{array}$ \\
\hline 10 & $\mathbf{F}$ & 41 & $\mathbf{R}$ & $\begin{array}{l}\text { optic } \\
\text { neuritis }\end{array}$ & $\begin{array}{l}1 \\
2 \\
3\end{array}$ & $\begin{array}{l}6 / 60 \\
6 / 18 \\
6 / 6\end{array}$ & $\begin{array}{l}6 / 5 \\
6 / 5 \\
6 / 5\end{array}$ & $\begin{array}{r}20 \\
70 \\
100\end{array}$ & $\begin{array}{l}103 \\
103 \\
103\end{array}$ & $\begin{array}{l}-83 \\
-33 \\
-\quad 3\end{array}$ & $\begin{array}{l}5 \cdot 2 \\
7 \cdot 1 \\
8 \cdot 2\end{array}$ & $\begin{array}{l}8 \cdot 3 \\
8 \cdot 5 \\
8 \cdot 5\end{array}$ & $\begin{array}{l}-3 \cdot 1 \\
-1.4 \\
-0.3\end{array}$ & $\begin{array}{l}-1.50 \\
-1.00 \\
-0.50\end{array}$ \\
\hline
\end{tabular}


meters were found as indicated in the following matrix:

$\begin{array}{lll} & \text { Threshold } & \text { Afferent defect } \\ \text { Acuity } & 0.86 & 0.93 \\ \text { Threshold } & & 0.91\end{array}$

The 2 patients with compressive lesions (nos. 5 and 7) had somewhat greater afferent defects than expected from their impairment of visual acuity. By contrast, the patient with a residual central scotoma following optic neuritis (no. 8) had no afferent defect despite severe impairment of acuity. A graphic plot of afferent defect against threshold difference (Fig. 3) shows that the former measurement relatively underestimated severe degrees of impairment. The linear regression between the measurements differed significantly from that expected from their complete agreement $(t=6 \cdot 68$, $\mathbf{P}<0.001$ ).

\section{Discussion}

The present study has demonstrated a pupillographic adaptation of the swinging flashlight test which can provide an objective assessment of the unilateral afferent pupillary defect. In normal persons the technique yielded close estimates of artificial defects, and in patients it provided measurements which correlated closely with both visual acuity and light perception threshold. In 2 patients with optic neuritis of recent onset repeated measurements over a period of 2 weeks showed a reduction in the

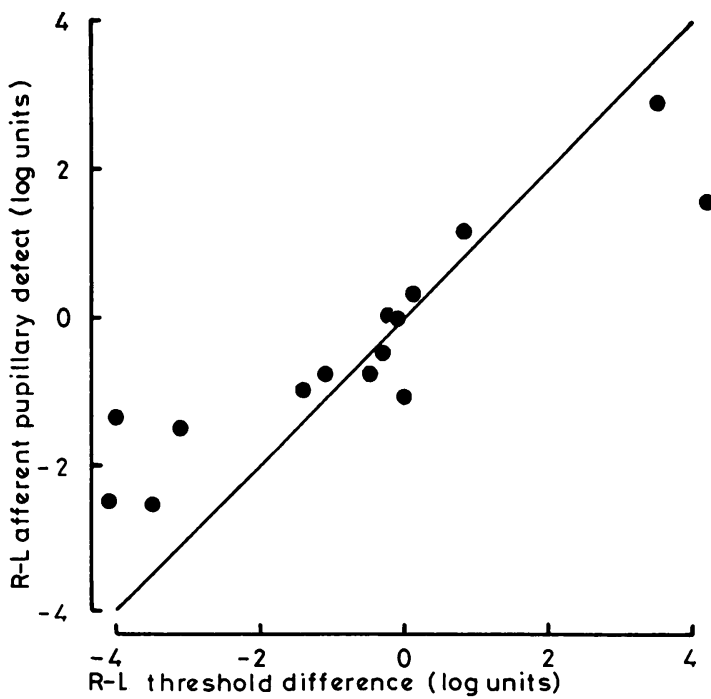

Fig. 3 Relationship between visual threshold difference and relative pupillary afferent defect $(\mathrm{n}=15)$.

Line drawn depicts agreement between the measurcments afferent pupillary defect which coincided with improvement in both acuity and light threshold. The technique can therefore provide unbiased confirmation of clinical recovery. With the exception of the VER all other tests used for the assessment of afferent visual pathway are subjective and liable to error in both patient and observer.

The measurements obtained on 3 of our patients revealed discrepancies between the magnitude of the afferent defect and impairment of visual acuity. In the conditions used it is likely that these arose because the 2 tests measured the function of different parts of the retina. While acuity involves macular vision, the pupillary response was elicited with light falling on the whole retina, representing a mass response. The exact size and position of the area stimulated is, however, uncertain. It is well known that at high intensities of illumination the visual acuity decreases as a result of dazzle (Moses, 1975). This decrease is believed to be a manifestation of neural inhibition within the retina.

It is inherent in the method that the assessment of the defect depends on the application of stimuli of different intensity to the 2 eyes. In the diseaseaffected eye, necessarily stimulated by the brighter light, there should be retinal adaptation (both photochemical and neural) to the greater stimulus (Newell and Ernest, 1974). If this occurred, our technique would have overestimated the magnitude of the defect, whereas by comparison with the visual threshold determination it was, in practice, underestimated. This finding cannot be explained at present, although it is possible that the pathological process directly affects neural light adaptation.

One obvious limitation of this technique is that it provides merely a comparison between the 2 eyes and it is less useful in patients with bilateral lesions. The same drawback has been noted by others studying optic nerve disease. Thus, Rushton (1975) noted this limitation among others when he reported the use of the Pulfrich pendulum to demonstrate abnormal delay in the visual pathway in patients with multiple sclerosis. Halliday et al. (1972) observed delayed latency in visual evoked responses to pattern-reversal stimulation in patients with optic neuritis, and they showed that some abnormal delay persisted after full clinical recovery. Using a similar technique, they later showed (Halliday et al., 1973) that clinically silent plaques of presumed demyelination could be demonstrated in the primary visual pathways of patients with multiple sclerosis, in whom optic neuritis had not occurred. These findings were substantiated by Asselman et al. (1975). It must therefore be emphasised that the technique used here can provide only a relative estimate of the afferent pupillary defect. 
Work is in progress in our laboratory to compare pupillographic and VER findings in healthy volunteers and in patients at intervals after episodes of optic neuritis. In this way it may be possible to localise demyelinating foci more accurately by comparing the anterior part (shown by the pupil response) with the combined anterior and posterior parts (shown by the VER) of the visual pathway. One object in our current studies is to establish standards for the magnitude and velocity of the pupillary light reflexes at different levels of illumination, against which defects arising from optic nerve damage can be assessed.

This work was supported financially by the Medical Research Council, the Prevention of Blindness Research Fund, and the Royal National Institute for the Blind, to whom we are grateful.

\section{References}

Asselman, P., Chadwick, D. W., and Marsden, C. D. (1975) Visual evoked responses in the diagnosis and management of patients suspected of multiple sclerosis. Brain, 98, 261-282.

Halliday, A. M., McDonald, W. I., and Mushin, J. (1972).
Delayed visual evoked response in optic neuritis. Lancet, 1, 982-985.

Halliday, A. M., McDonald, W. I., and Mushin, J. (1973). Visual evoked response in the diagnosis of multiple sclerosis. British Medical Journal, 4, 661-664.

Harris, H., and Kalmus, H. (1949). The measurement of taste sensitivity to phenylthiourea (PTC). Annals of Eugenics, 15, 24-31.

Levatin, P. (1959). Pupillary escape in disease of the retina or optic nerve. Archives of Ophthalmology, 62, 768-779.

Lowenstein, O. (1954a). Clinical pupillary symptoms in lesions of the optic nerve, optic chiasm and optic tract. Archives of Ophthalmology, 52, 385-403.

Lowenstein, O. (1954b). Alternating contraction anisocoria; pupillary syndrome of anterior midbrain. Archives of Neurology and Psychiatry, 72, 742-757.

Moses, R. A. (ed.) (1975). Adler's Physiology of the eye: clinical applications, 6th edn., p. 503. Mosby: St. Louis. Newell, F. W., and Ernest, J. T. (1974). Ophthalmology: Principles and concepts, 3rd edn., p. 83. Mosby: St. Louis.

Rushton, D. (1975). Use of the Pulfrich pendulum for detecting abnormal delay in the visual pathway in multiple sclerosis. Brain, 98, 283-296.

Snedecor, G. W., and Cochran, W. G. (1967). Statistical Methods, 6th edn. Iowa State University Press: Ames.

Snell, A. C., and Sterling, S. (1925). The percentage evaluation of macular vision. Archives of Ophthalmology, 54, 443-461.

Thompson, H. S. (1966). Afferent pupillary defects. American Journal of Ophthalmology, 62, 860-873. 